\title{
Review Article \\ Bacteria in Cancer Therapy: Renaissance of an Old Concept
}

\author{
Sebastian Felgner, ${ }^{1}$ Dino Kocijancic, ${ }^{1}$ Michael Frahm, ${ }^{1}$ and Siegfried Weiss ${ }^{1,2}$ \\ ${ }^{1}$ Department of Molecular Immunology, Helmholtz Centre for Infection Research, 38124 Braunschweig, Germany \\ ${ }^{2}$ Institute of Immunology, Hannover Medical School, 30625 Hannover, Germany
}

Correspondence should be addressed to Sebastian Felgner; sebastian.felgner@helmholtz-hzi.de

Received 23 September 2015; Revised 3 February 2016; Accepted 11 February 2016

Academic Editor: Todd R. Callaway

Copyright (C) 2016 Sebastian Felgner et al. This is an open access article distributed under the Creative Commons Attribution License, which permits unrestricted use, distribution, and reproduction in any medium, provided the original work is properly cited.

\begin{abstract}
The rising incidence of cancer cases worldwide generates an urgent need of novel treatment options. Applying bacteria may represent a valuable therapeutic variant that is intensively investigated nowadays. Interestingly, the idea to apply bacteria wittingly or unwittingly dates back to ancient times and was revived in the 19th century mainly by the pioneer William Coley. This review summarizes and compares the results of the past 150 years in bacteria mediated tumor therapy from preclinical to clinical studies. Lessons we have learned from the past provide a solid foundation on which to base future efforts. In this regard, several perspectives are discussed by which bacteria in addition to their intrinsic antitumor effect can be used as vector systems that shuttle therapeutic compounds into the tumor. Strategic solutions like these provide a sound and more apt exploitation of bacteria that may overcome limitations of conventional therapies.
\end{abstract}

\section{Introduction}

For most patients, cancer diagnosis remains equivalent to suffering, intoxicating therapies and an impending fatal outcome. Very little has changed to this perception over the past fifty years. Despite intensive research as well as improved classical and newly developed therapies, cancer remains the second most frequent cause of death in industrialized societies. Adequate prophylaxis or treatment of other diseases, like cardiovascular disease or infections, has reduced the death toll for these conditions and has dramatically increased life expectancy. However, cancer is essentially a disease of old age. Many molecular alterations are required in the genome of a cell to transform a normal cell into a cancer cell. Thus, the likelihood that such events take place in an individual cell is increasing with age. This also partly explains the rising incidence of cancer. Based on recent official statistics, every second individual will be diagnosed with cancer throughout his life and every fourth will eventually succumb to the disease [1]. This fact illustrates the tremendous impact of cancer on modern society and the need for suitable therapies that can cure it.

Conventional therapies like surgery, radiotherapy, or chemotherapy remain the backbone of cancer therapy to date.
However, not every cancerous tissue can be targeted with a scalpel and physical and chemical methods in general do not distinguish between healthy and malignant tissues $[2,3]$. In order to overcome these drawbacks, extensive research was carried out to widen the knowledge on carcinogenesis. This revealed cancer as a highly complex and multifactorial type of disease $[4,5]$. Hanahan et al. have conveniently summarized this research and defined ten particular characteristics, termed "hallmarks" of cancer, which equally highlight potential starting points for novel therapies $[6,7]$.

In this context, immune surveillance is now generally accepted as the hosts own defense system against the development of cancer. However, tumors may become resistant to immune destruction through mechanisms of immune editing or Darwinian selection $[8,9]$. Thus, under such circumstances a "mutator phenotype" may prevail which not only counterbalances immune surveillance but also overturns it. Physiological consequences of this imbalance may lead to a tumor microenvironment of "repair" rather than "destruction" [9]. Active cancer immunotherapy aims to reverse this imbalance through compensatory immune activity. The ultimate aim of such therapies is to achieve not only transient effects but also long lasting antitumor effects through engaged immunological memory. After years of 
research and many set-backs, some cancer immunotherapies have become available in the clinics [10-13]. Therefore, Science magazine selected cancer immunotherapy as the scientific breakthrough of the year in 2013.

Considering all the efforts and difficulties in this therapeutic development before reaching sound therapeutic candidates, it is surprising that the first systematically applied cancer immunotherapy used in more than a thousand patients dates back to a time where radiotherapy and chemotherapy had not yet been invented.

\section{William Coley: Lessons Learned from the Past}

The idea of using bacteria in cancer therapy is often presented as a new approach but in reality predates that of conventional therapies by a long run. The first report describing a connection between infections and a treatment of so-called swellings (most likely cancerous tissue) was documented by the Egyptian physician Imhotep 2600 BC [14]. During the course of history, similar examples can be found. More recently, in 1813, tumor retardation was also observed in cancer patients suffering from gas gangrene, nowadays known to be caused by Clostridia sp. [15]. Likely intrigued by historical examples, the first "clinical trial" was performed by W. Busch and colleagues in Berlin in 1863. They intentionally infected a female cancer patient by transferring her into a contaminated bed in which a patient had died from Erysipelas, an infection caused by Streptococcus pyogenes. As expected, the patient became infected. As a result, the tumor did regress; however, also the patient died from the infection $[16,17]$. The inability to control bacterial infections at that time was limiting its general clinical application.

Inspired by history and uncontrolled trials, the American physician William Coley (1862-1936) became the first pioneer of cancer immunotherapy. Although Coley also started with live bacteria, capable of killing his patients, he was the first to notice that an accurate balance between the therapeutic benefit and infection control was essential for feasibility of this type of treatment. As a solution, he applied a mixture of heat-inactivated Streptococcus pyogenes and Serratia marcescens, known as "Coley's toxin," to many patients afflicted with inoperable sarcomas. The treatment was very effective. During his career, he applied his "toxin" to more than 1000 cancer patients. Whenever possible, he injected it directly into, or in close proximity to, the primary tumor mass and kept increasing the dose over the course of therapy [1719]. As a common side effect, he observed episodes of fever. According to his records, a lengthy treatment and onset of fever were correlating with the success of the therapy [20-22]. Tumor regression was observed in many cases and for some patients even complete clearance of the primary tumor mass and a disease-free state were obtained [20].

Although Coley's work was met with certain success at the time, his work was not acknowledged and rather forgotten until the approach had been approved by the American Medical Association in 1936, after the death of W. Coley. A possible reason for this development might have been the inability to explain the therapeutic mechanism and to control bacterial infections or side effects of the therapy. At the same time, the possibility of radiotherapy was emerging and providing a competitive alternative to bacteria mediated cancer therapy. Prohibiting advancement of Coley's therapy was certainly also the standpoints of leading US cancer pathologists who strongly opposed Coley's therapeutic approach [20]. Although bacteria mediated tumor therapy was still subject to investigation after Coley's death, it had been marginalized for decades. In the 1960s and 1970s, small clinical trials were performed with formulations similar to Coley's toxin (e.g., Vaccineurin) but the results were variable. Furthermore, a controlled study performed in 1962 showed a therapeutic response in 20 out of 93 cancer patients indicating a difference in individual susceptibility to this kind of therapy [23]. However, it is important to note that a comparison between Coley's therapy and later attempts should take into consideration differences in the specific formulation, the course of treatment including duration and frequency, and prior or simultaneous application of chemotherapeutic and antipyretic drugs [24].

Nevertheless, bacteria can be found in the clinics as routine treatment for cancer patients nowadays. Since the late 1980 s, oncologists were successfully using the vaccine variant of Mycobacterium bovis BCG (Bacille Calmette-Guerin) as agent to prevent relapses of bladder cancer after surgical removal of the primary tumor [25]. Although the exact mode of action of the bacteria is not fully understood, they might enhance the immune response against the cancer cells by, for example, activation of natural killer cells [26-29]. Also the idea to use bacteria systemically is undergoing renaissance. The progress in biomedical research as well as the increasing knowledge on bacterial behavior and genetic engineering is most likely the reason for the enhanced attention on bacterial tumor therapy.

\section{Current Concepts of Bacteria Mediated Cancer Therapy}

Using animal models, several Gram-positive and Gramnegative bacteria of various genera including Clostridia sp., Salmonella sp., Bifidobacteria sp., and Listeria sp. have already been tested for their potential in cancer therapy. Table 1 summarizes former and recent results of representative studies dealing with bacterial therapies.

In the last half of the 20th century, obligate anaerobic bacteria like Clostridia spores were preferentially used for cancer therapy. Their spores germinate only in the absence of oxygen. Therefore, these bacteria are specific for necrotic areas, a frequent and unique characteristic of solid tumors [30-33]. Thus, they should provide a high safety profile in patients. Although germination of Clostridia was indeed confined to hypoxic regions, toxicity conferred by exotoxins led to high mortality rates using this type of bacteria. To increase the safety of Clostridia, virulence factors like the $\alpha$-toxin had been deleted from potential therapeutic strains. Aside from experimental studies in mice, C. novyi-NT (nontoxic) has already been tested in preclinical and clinic trials using dogs as well as human patients (see Table 2). Results were promising and the advanced leiomyosarcoma 
TABLE 1: Recent representative preclinical examples of bacteria mediated tumor therapy (BMTT) in vivo from 2012 onwards.

\begin{tabular}{|c|c|c|c|c|}
\hline Species & Year & Model & Result & References \\
\hline C. novyi & 2014 & Spontaneous, dog & Colonization and prolonged survival & {$[34]$} \\
\hline C. novyi & 2015 & Glioblastoma, rat & Colonization and prolonged survival & [35] \\
\hline B. infantis & 2013 & Bladder, rat & High tumor specificity by engineered strain & {$[129]$} \\
\hline L. monocytogenes & 2014 & Ovary, mouse & Reprogramming of M2-M $\phi$, iNOS-mediated tumor cell lysis & {$[130]$} \\
\hline $\begin{array}{l}\text { L. monocytogenes } \\
\text { (ANZ-100) }\end{array}$ & 2014 & Pancreas, mouse & Prolonged survival & {$[131]$} \\
\hline $\begin{array}{l}\text { S. Typhimurium } \\
\text { (Al-R) }\end{array}$ & 2012 & Breast, nude mouse & Intravenous administration most effective for tumor targeting & {$[132]$} \\
\hline $\begin{array}{l}\text { S. Typhimurium } \\
\text { (Al-R) }\end{array}$ & 2012 & Brain, nude mouse & Tumor growth inhibition and prolonged survival & {$[133]$} \\
\hline $\begin{array}{l}\text { S. Typhimurium } \\
\text { (A1-R) }\end{array}$ & 2014 & Bone metastasis, nude mouse & Inhibition of breast cancer bone metastasis & {$[47]$} \\
\hline $\begin{array}{l}\text { S. Typhimurium } \\
\text { (A1-R) }\end{array}$ & 2014 & Pancreas, nude mouse & Tumor growth retardation, A-VEGF supports therapy & {$[134]$} \\
\hline $\begin{array}{l}\text { S. Typhimurium } \\
\text { (A1-R) }\end{array}$ & 2015 & Ovary, nude mouse & Prolonged survival, less metastasis formation & {$[51]$} \\
\hline S. Typhimurium & 2015 & Carcinoma (CT26), mouse & Complete tumor rejection in all cases by recombinant strain & {$[54]$} \\
\hline E. coli & 2015 & Breast (4T1), mouse & Secretion of toxic compound, reduced tumor volume & {$[113]$} \\
\hline La. acidophilus & 2014 & Carcinoma (CT26), mouse & Increased apoptosis and tumor growth suppression & {$[135]$} \\
\hline
\end{tabular}

TABLE 2: Recent examples of clinical trials with bacteria mediated tumor therapy (BMTT) since 2002.

\begin{tabular}{|c|c|c|c|c|}
\hline Species & Year & Cohort & Result & References \\
\hline $\begin{array}{l}\text { S. Typhimurium } \\
\text { (VNP20009) }\end{array}$ & 2002 & $\begin{array}{l}24 \text { patients with metastatic melanoma; } 1 \\
\text { patient with metastatic renal cell carcinoma }\end{array}$ & $\begin{array}{l}\text { Induction of immune response, tumor } \\
\text { colonization in } 3 \text { cases, no antitumor } \\
\text { response }\end{array}$ & {$[53]$} \\
\hline $\begin{array}{l}\text { S. Typhimurium } \\
\text { (TAPET-CD) }\end{array}$ & 2003 & $\begin{array}{l}3 \text { patients with advanced and metastatic } \\
\text { solid tumors }\end{array}$ & $\begin{array}{l}66 \% \text { tumor colonization, measurable } \\
\text { activity of cytosine deaminase in tumor }\end{array}$ & {$[107]$} \\
\hline C. novyi-NT & 2014 & 1 patient with advanced leiomyosarcoma & $\begin{array}{l}\text { Tumor reduction within and surrounding } \\
\text { the bone }\end{array}$ & {$[34]$} \\
\hline C. novyi-NT & Active & $\begin{array}{l}\text { Patients with solid tumors that do not } \\
\text { respond to standard therapy }\end{array}$ & Recruitment (NCT01924689) & - \\
\hline $\begin{array}{l}\text { L. monocytogenes } \\
\text { (ANZ-100 and } \\
\text { CRS-207) }\end{array}$ & 2011 & $\begin{array}{l}26 \text { patients with solid tumors (liver, } \\
\text { pancreas, lung, or ovary) }\end{array}$ & $\begin{array}{l}\text { Safe vaccines that resulted in immune } \\
\text { activation }\end{array}$ & {$[64]$} \\
\hline $\begin{array}{l}\text { L. monocytogenes } \\
\text { (CRS-207) }\end{array}$ & Active & 90 patients with pancreatic cancer & Extended survival with minimal toxicity & {$[136]$} \\
\hline
\end{tabular}

C. = Clostridium; L. = Listeria; S. = Salmonella.

of a human patient was positively affected upon intratumoral injection of Clostridia spores [34]. Furthermore, in a recently published report, orthotopic glioblastomas were successfully targeted with C. novyi spores upon intravenous infection in a rat model [35]. These data indicate that the spores are able to pass the blood brain barrier under certain conditions. Although the mechanism of the antitumor effect by Clostridia is poorly understood, these bacteria are able to successfully target neoplastic tissue without seriously harming the host. Therefore, they might represent a suitable carrier in bacteria mediated tumor therapy. However, the restriction to anaerobic regions might also be a great disadvantage of Clostridia. Metastases or small tumors without necrotic areas as colonizing niche may not be targeted as easily by this therapeutic approach.

To overcome the limitation of confinement to hypoxic regions and to address the problem that tumors outgrow from viable oxygenated tissue, facultative anaerobic bacteria like Salmonella Typhimurium moved into focus of bacteria mediated cancer therapy. However, as Salmonella are able to grow under aerobic conditions, they are not restricted to only colonizing tumors but are also able to disseminate to healthy organs like spleen and liver [36]. To ensure safe application, Salmonella need to be adapted. Coley already realized that a level of control is needed for the success of his therapy. As he had observed for $S$. pyogenes, wild-type bacteria are 
efficiently capable of attacking cancerous tissue, however not without compromising patients' safety. In an attempt to solve this problem, he adhered to heat inactivation, albeit noticing a decrease in therapeutic efficacy [18]. Rather than crude heat inactivation, later attempts have sought to reinstall safety via means of attenuation by genetic alteration.

Nowadays, suitable strains have been generated. They are obtained either by in vitro or in vivo passaging or by targeted gene deletion using molecular techniques [37-40]. The first technique relies on the selective pressure when the bacteria adapt to a particular environment within the host. By passaging bacteria from tumor to tumor either in cell culture or in mice, they can develop a tumor adapted phenotype concurrently exhibiting high tumor specificity. The prominent Salmonella strains VNP20009 (in vitro) and A1-R (in vitro and in vivo) emerged from this type of strategy [41-43]. Auxotrophy for purines or Arg and Leu, respectively, rendered these Salmonella variants metabolically deficient and increased tumor specificity. Particularly, the strain A1$\mathrm{R}$ was shown to be highly effective in various cancer models [44-51]. However, the random introduction of certain deletions or single point mutations through selective pressure represents an uncontrollable way to properly tailor bacterial strains. It was reported that VNP20009 was coincidentally bearing a deletion of 120 genes that might affect its in vivo performance [52]. In addition, it contains a SNP in the chemotaxis gene cheZ. As consequence, the whole flagella synthesis is impaired. The strain was therefore devoid of a potent immune-stimulating factor. Decreased immunogenicity may provide one explanation for the poor outcome of the clinical trial performed with this strain in 2001 [53]. Due to the uncertainties affiliated with such an unspecific method of attenuation illustrated by the previous examples, targeted gene deletion may be a better choice for tailoring bacteria for cancer therapy.

The intrinsic antitumor response of bacteria is most likely connected to their microbial associated molecular patterns (MAMPs) like LPS, flagella, and CpG [54-57]. Some of these molecules represent suitable targets for modification. However, such modifications can easily lead to overattenuation that might increase their safety but at the same time compromise their ability to induce a sufficient antitumor response. Nevertheless, the trial and error concept of finding proper bacterial variants of Salmonella that can safely stimulate immunity against the tumor was leading to the discovery of the aforementioned candidates VNP20009 and A1R which have already been tested in various preclinical setups and/or clinical trials. Even though the antitumor response induced by Salmonella is partially understood nowadays (Figure 1), designing them properly for therapy remains challenging [58]. As seen in Figure 1, a strong induction of the innate immune system, for example, high levels of TNF- $\alpha$, is initiated by Salmonella to promote colonization of solid tumors $[59,60]$. This is accompanied by a Salmonellainduced adjuvant effect concurrently activating the adaptive immune response. As consequence, tumor-specific cytotoxic $\mathrm{T}$ lymphocytes (CTL) that are able to destroy the remaining cancerous tissue have been found to increase in numbers [61].

\section{Clinical Trials: Lessons Learned for the Future}

Prominent representatives of the genera Listeria, Clostridia, and Salmonella have made it into clinical trials. However, while Listeria monocytogenes (ANZ-100) was primarily tested as a recombinant attenuated therapeutic live vaccine for advanced cancer patients [62-64], the trials with Clostridia and Salmonella relied predominantly on the intrinsic antitumor effect of the bacteria (Table 2).

For instance, in 1947, the first bacterial filtrates of $C$. histolyticum spores entered clinical trials [65]. Although preferential accumulation in the cancerous tissue along with antitumor effects was observed, the systemic toxicity induced by exotoxins released from the bacteria was too high. Furthermore, the inefficiency of Clostridia spores in normoxic areas most likely facilitated tumor regrowth [66]. As consequence, recent clinical trials were performed with nonpathogenic Clostridia sp. such as Clostridia butyricum M-55 or Clostridia novyi-NT (Table 2). In 2012, six client-owned dogs, nonresponsive to standard therapy, were treated with C. novyi-NT. Again, the spores preferentially germinated in the tumor but were still able to induce some acute toxic effects including fever, nausea, and diarrhea [67]. Despite these side effects, the authors suggested to carry on with clinical trials [66]. Accordingly, Roberts and colleagues treated a human patient with an advanced leiomyosarcoma and observed ongoing tumor regression after several intratumoral applications of spores [34]. We believe that this will serve as a basis for further clinical trials. While it is now established that the antitumor effect of Salmonella relies on an induced anticancer immune response $[59,68]$, the therapeutic mechanisms of Clostridia have not yet been studied in detail. Considering the local effects of germination during infection, the response might be mediated by direct histolytic activities. In accordance, the mechanism of tumor invasion, the mode of action, and the role of the immune system need to be investigated in order to optimize the cancer therapy with spores of Clostridia.

In case of Salmonella, the highly attenuated strain VNP20009 was tested in humans and dogs in 2002 and 2005 , respectively $[53,69]$. This strain had been specifically designed for bacterial cancer therapy. It exhibits a purI ${ }^{-}$ $x y l^{-}$genotype and was shown to be hyperinvasive in human M2 melanoma cells [70]. Additionally, $m s b B$ gene had been deleted to render Lipid A molecule less immunogenic [71, 72]. While this strain was shown to colonize murine tumors efficiently and exhibit strong antitumor effects, the results in canine and human hosts were not as prominent $[53,69]$. In dogs, colonization in only $42 \%$ of subjects was accompanied by a response rate of $25 \%$, while colonization and therapeutic response in the human environment almost failed completely. This comparison illustrates the translational challenge in turning from one host to the other, that is, from transplantable tumors in mice to the application in humans.

Bacteria are known to be more resistant towards murine effector mechanisms. In support, the human trial did show that most of the bacteria were cleared from the circulation within $60 \mathrm{~min}$. This might suggest a distinguishing role of complement lysis and phagocytic clearance upon systemic 


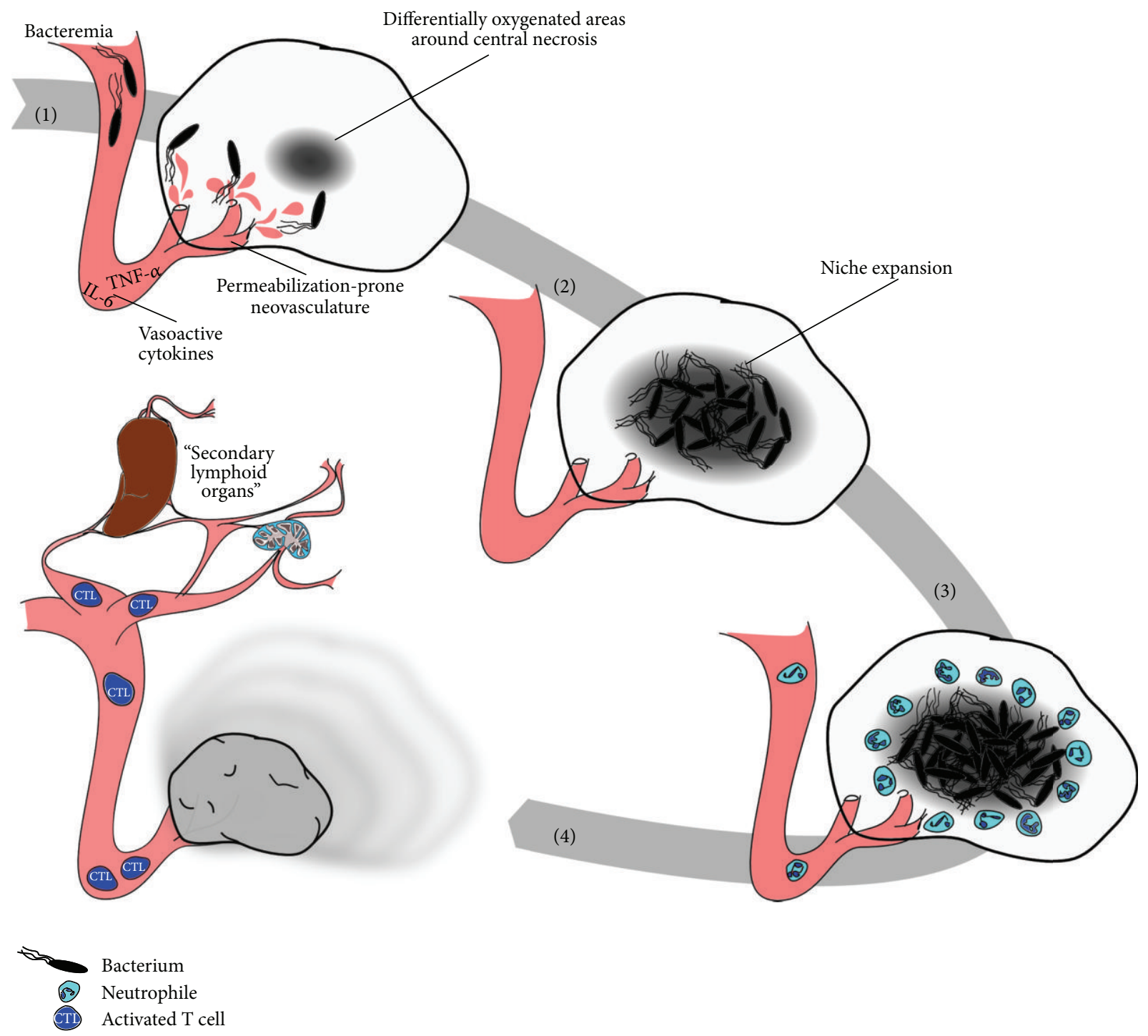

FIGURE 1: Biological events of the intrinsic tumor therapeutic effect of Salmonella. Steps (1)-(4) depict major biological events associated with an antitumor effect induced by Salmonella infection. (1) Tumor invasion. (2) Colonization. (3) Infection control. (4) Antitumor response and tumor regression. (1) Presence of bacteria in the blood stream (bacteremia) induces a cytokine storm, which is dominated by vasoactive cytokines that facilitate passive deposition of bacteria in the tumor during the induced hemorrhage. (2) Invading bacteria accumulate, localize to a preferable growth environment (low $\mathrm{p}_{2}$, immune privileged site), and proliferate to saturation. (3) Colonization brings about change to the tumor microenvironment, including attraction and polarization of innate effector cells and cytokines in favor of antibacterial control and tumor immune surveillance. (4) Tumor regression occurs in response to multimodal therapeutic effects, including an adjuvant effect on preestablished tumor immune surveillance, polarization of innate effectors' phenotype, direct cytotoxicity, and passive effects.

application to human patients. Such are most important aspects to consider for a successful cancer therapy using bacteria [54]. Furthermore, mice were usually kept under specific pathogen-free conditions and had not been preexposed to Salmonella Typhimurium prior to the therapy. In contrast, some humans and dogs may have been preexposed and therefore already possess immunity to the bacteria to a certain level [73]. Moreover, one also needs to carefully consider the pretreated state of the patients in these particular trials. Human patients were often preexposed to chemotherapeutics, which may per se impact the immune system and thus reduce its responsive capacity. Along the same line, a discrepancy may arise from a cohort selection of late-stage cancer patients that may already have been highly immune compromised. In particular a therapy with a mode of action that predominantly relies on the activation of an immune response might crumble under these preconditions. One possible explanation why Coley was so successful may be that he deployed his mixture as first-line treatment or after surgical resection [18].

Reviewing Coley's work, another important aspect should be discussed; namely, does tumor colonization constitute a prerequisite for a therapeutic effect or is the whole process sufficiently initiated by the bacterial induced cytokine storm 
following bacteremia? Coley was using heat-inactivated bacteria which are unable to establish colonization of solid tumors. Regardless, antitumor activity was still observed in most of his cases. It was suggested that streptokinase of S. pyogenes might constitute an effector molecule of Coley's toxin [74]. However, heat inactivation would have also affected production and secretion of this particular molecule. Nowadays, it is known that bacteria express so-called MAMPs which are recognized by pattern recognition receptors and are to a large extent heat stable. They stimulate cells of the immune system which are at least partly responsible for the therapeutic activity. In accordance, mice that either are lacking the Tolllike receptor 4 (TLR4) or are defective in MyD88 signaling did not display any antitumor response upon administration of Salmonella [75, 76]. Along this line, single injection of LPS alone has been shown in particular tumor models to elicit strong antitumor effects in Wt mice and induce specific tumor responses [59]. Therefore, tumor colonization might not be an essential driving force, but rather the MAMPs provided may act as adjuvant for priming or activating the immune system at inductive lymphoid organs. This, however, remains speculative. More work is needed to elucidate the intermittent relationship between traits of bacterial infection and an antitumor effect. Nevertheless, currently various purified or synthetic MAMPs are evaluated in preclinical and clinical trials (reviewed in [77]).

In the 2001 clinical trial, the VNP20009 strain of Salmonella was administered to cancer patients with metastatic melanoma. In the vast majority of cases, with a few exceptions, VNP20009 failed to colonize tumors. Hence, any antitumor response must have been initiated by MAMPs supplied from sites extrinsic to the tumor. However, also no significant antitumor effects were observed among the patient cohort in this particular study. Studies in mice have shown that while some highly immunogenic tumors like the colon carcinoma CT26 can be easily affected with systemically applied purified LPS or dead bacteria, more resilient tumors like RenCa (a renal adenocarcinoma) may not be similarly affected by the same treatment [54]. Therefore, the efficacy of a MAMP-based therapy depends not only on the potency of the bacterial infection but also on the immunogenicity of the tumor or the effectiveness of its escape mechanisms.

Explanations for the failure of VNP20009 may be numerous. On one hand, the previously mentioned influence of prior chemotherapeutic treatment on immune cells may have had an impact on the efficacy of the therapy. On the other hand, the strain may have been simply overattenuated for the human immune system, meaning that VNP20009 was probably cleared long before it was able to induce a proper immune response or establish tumor colonization. In particular, the aforementioned large gene deletion and the abolished flagellar synthesis could have had dramatic effects on the fitness and immunogenicity of the bacterial strain (e.g., by its inability to trigger TLR5 via flagellar PAMPs [78]). Based on these considerations a new concept of strain design has to be defined to appropriately enhance the immunogenicity of a mutant strain while retaining its attenuated character.

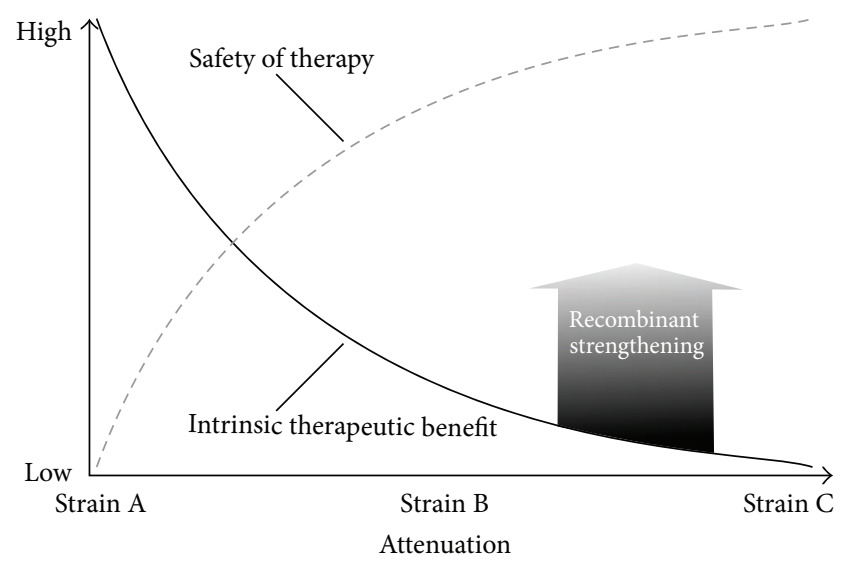

FIGURE 2: Hypothetical relationship between intrinsic therapeutic benefit and safety using Salmonella for bacteria mediated tumor therapy. Empirical observations support an inverse relationship between intrinsic therapeutic benefit and safety of treatment associated with Salmonella-based tumor therapy. Strain variants A-C in order of increased attenuation. Depicted are three scenarios, each intrinsically inadequate for achieving therapeutic success. Reinstalling/complementing an intrinsic therapeutic effect may be accomplished via recombinant strengthening without affecting the aforementioned intrinsic relationship.

\section{Optimal Tumor Targeting Salmonella Strains: Requirements and Promising Strategies}

Interestingly, the lessons learned from recent clinical trials are similar to those Coley made nearly hundred years ago. Although the technology was not available to genetically modify microorganisms like Streptococcus at that time, Coley's heat inactivation approach generated a proper balance between therapeutic benefit and safety nevertheless (Figure 2). At the very least, one may have deemed it a success under the set of conditions he was facing regarding patient status, that is, no chemotherapy and first line therapy. Nowadays, the requirements are different and genetic engineering is essential to tailor bacteria for cancer therapy.

Again, it is important to emphasize that for therapeutic success an ideal balance between immune stimulation and attenuation has to be determined and reached by strain design (Figure 3). Previous studies have shown that single gene deletions are sufficiently able to attenuate Salmonella in a murine environment $[54,60,71,79-81]$. Several of these deletion strategies either interfere with virulence factors (i.e., important MAMPs) or restrict the in vivo survival of the bacteria by metabolic auxotrophies $[82,83]$. However, as mentioned in the previous section, only focusing on rendering a bacterium safe for administration might not be the proper solution to achieve a suitable strain for cancer therapy. Take, for example, Salmonella variants that lack an essential parts of the LPS molecule (e.g., $\Delta r f a D$ ). Mice are symptomless upon infection with this particular mutant strain. However, drastically reduced antitumor effects were observed [54]. 


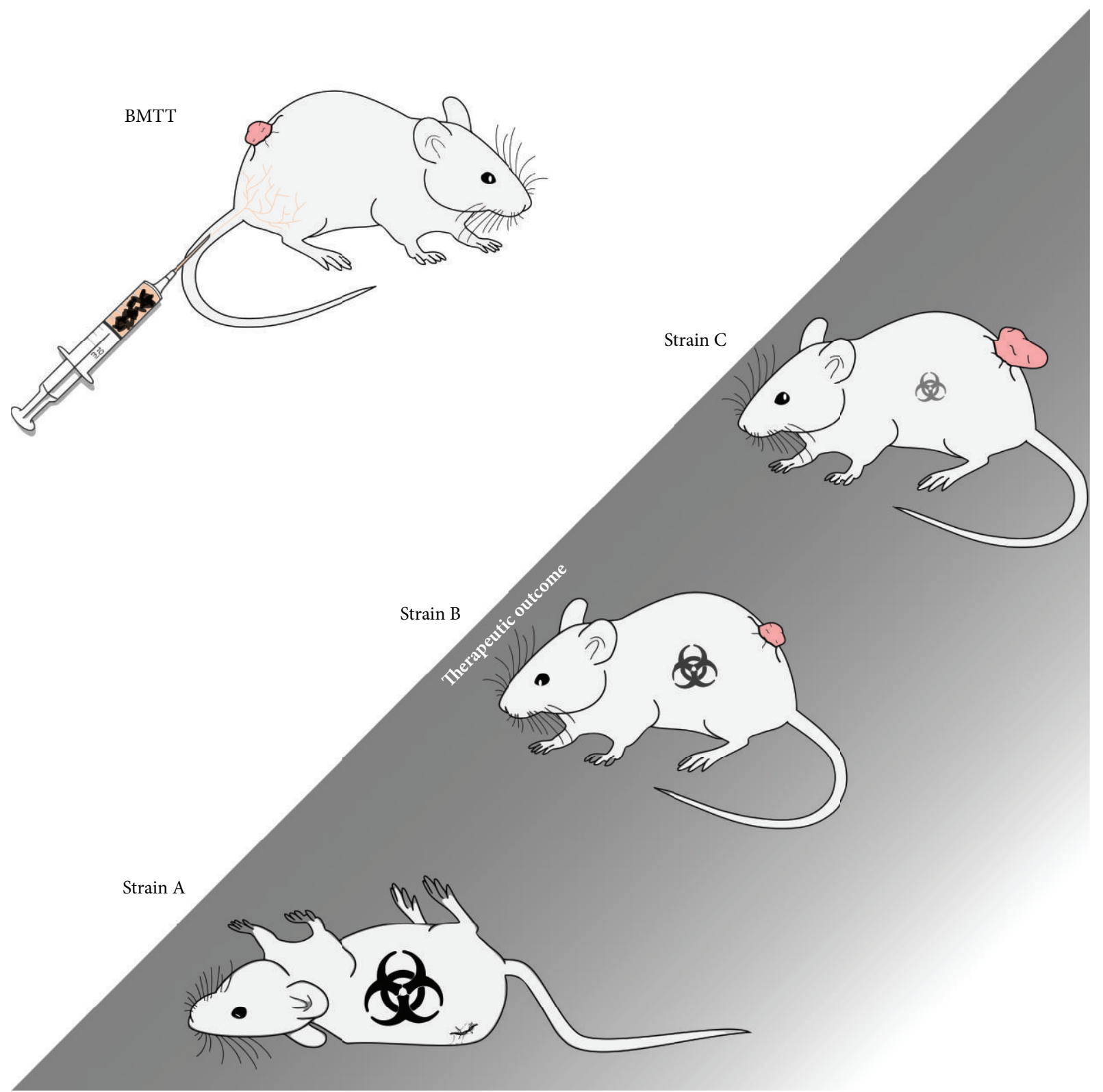

Severity of infection

FIGURE 3: Various phenotypic outcomes in mice following treatment with Salmonella. The inverse relationship between intrinsic therapeutic benefit and safety of bacteria mediated tumor therapy (BMTT) using Salmonella can be demonstrated through manifestation and progression of cancer and infection in mice. An inadequately attenuated, thus virulent, strain may successfully retard/regress tumor development albeit concurrently resulting in morbidity and mortality of the patient (strain A). Conversely, overattenuation may ensure patient safety at the cost of therapeutic efficacy (strain C). Intermediate levels of attenuation may yield corresponding levels of cancer progression and manifestation of infection (strain B). Thus, developing a properly balanced strain remains a challenge for successful therapy using Salmonella.

The conclusion is that the strain had been overattenuated. Based on these findings, it is not advisable to shut down bacterial virulence factors that are obviously important for inducing the essential immune response for therapeutic effects. Hence, a bacterial strain has to be designed by genetic engineering in a way that the microorganism is both attenuated and optimized at the same time. Along these lines, several interesting approaches have been tested for vaccination purposes in the past few years that could potentially be transferred to cancer therapy [38].

One approach is to generally increase the adjuvant effect of bacteria. The immune recognition of Salmonella and induction of an immune response directly correlate with the presence of various MAMPs. To survive in a hostile environment Salmonella may either modify the structure of the MAMP or downregulate the expression of certain 
immunogenic factors like flagella [72, 84-86]. To counteract such mechanisms, a promising recombinant strategy would be to reinstall the immunogenicity of Salmonella via modification of immunogenic targets/MAMPs. For example, a hexaacylated Lipid A structure was shown to be highly efficient at stimulating TLR4, while tetra-acylated Lipid A acts as an antagonist [87]. Therefore, a mutant ( $\triangle p a g P \triangle p a g L \Delta l p x R)$ only expressing the hexa-acylated Lipid A structure was shown to enhance the therapeutic effect $[72,88]$. In addition, it was shown that Salmonella variants bearing both flagella proteins FliC and FljB trigger an increased host immune response upon oral administration $[89,90]$. These examples demonstrate that the immunogenicity of attenuated bacteria can be enhanced when the MAMPs are modified in a way that host pattern recognition receptors (PRR) are more efficiently stimulated.

However, modifying the expression of certain MAMPs could have pleiotropic effects, some detrimental, that may affect the regulatory circuits of bacteria in a more general way. Therefore, a wild-type like phenotype of bacteria that is only conditionally modified may be the next step in strain design. Currently, two concepts are evaluated using this rationale, namely, delayed attenuation and delayed lysis [38, 54, 9196]. Such mutants exhibit a wild-type like phenotype upon in vivo administration while carrying a modified genotype. For instance, auxotrophic/attenuated bacteria may express a complementing gene under an inducible promoter like $\mathrm{P}_{\mathrm{BAD}}$ or $\mathrm{P}_{\text {tet }}$. Their activation depends on presence of arabinose or anhydrotetracycline, respectively. Such bacteria can be inducibly complemented in culture. In vivo, the inducers are diluted out and no longer available. As consequence, the bacteria will lose their WT phenotype and become attenuated after a few rounds of replication. This delayed attenuation system was recently deployed for Salmonella to modify the LPS structure under the control of $\mathrm{P}_{\mathrm{BAD}}$. The effect was evaluated in a murine tumor model [54]. The wild-type like phenotype of the administered bacteria induced a strong immune response that significantly enhanced the antitumor response compared to the bacteria carrying the gene deletion only. None of the mice succumbed to the infection and the health status of the mice was only transiently affected after bacterial administration [54].

Similarly, in the delayed lysis system cell wall synthesis is abrogated in the absence of arabinose in vivo [97]. The bacteria are thus not able to establish a systemic infection. However, the sudden cell death in vivo might cause complications like toxic shock due to release of large amounts of endotoxin and other PAMPs. Nevertheless, the system was successfully tested to vaccinate mice against influenza viruses, by a targeted release of intracellular virus specific antigens by the bacteria [98]. The system may be no less useful in a cancer model and should thus be explored.

These results demonstrate that modern strategies may accommodate attenuation and optimization in the same therapeutic strain. Nevertheless, many tumors still remain completely resistant to such a therapy or might only be delayed in growth. The technological progress has now fostered the possibility to modify bacteria not only to the needs of safety but also to the needs of efficacy. The possibility of simply focusing on intrinsic therapeutic effects has been challenged. In this regard, combining chemotherapeutic approaches together with bacteria may represent a more realistic and promising strategy for ongoing research efforts $[48,99,100]$. In particular, the combination with checkpoint inhibitors like $\alpha$-PDL1 or $\alpha$-CTLA4 has shown increased efficacy [101-103]. However, in this review, we restrict our focus to the strategy of W. Coley and the possibilities in recombinant strengthening of tumor targeting bacteria. Bacteria could be designed to shuttle therapeutic compounds like chemotherapeutic drugs directly into the cancerous tissue. This should maximize their effect while reducing systemic side effects. Bacteria with their intrinsic tumor specificity provide a unique tool kit for this application.

\section{Bacteria as Tumor Targeting Shuttles of Therapeutic Molecules}

Exploiting bacteria as live vector systems could represent the next generation of strain design. However, this promising idea is affiliated with its own challenges [104]. A tumorspecific bacterium and a compound that can be synthesized and, if necessary, actively secreted by the bacteria are both required.

Two concepts are currently under investigations. The first one employs prodrug converting enzymes produced by bacteria. This strategy relies on enzymes that are capable of converting a systemically administered inactive prodrug into an active cytotoxic "drug." As the enzyme would be present only in vicinity of the bacteria and facilitate conversion at only this site, this therapy requires high tumor specificity to ensure local efficacy and activity only against the target tumor. The therapeutic benefit of enzymes like cytosine deaminase and nitroreductase expressed by either Clostridia or Listeria has been tested [105-110]. However, while they showed promising activity in vitro, no significant improvement of therapeutic effects was observed in vivo. Most likely, the expression levels or the efficacy of secretion or conversion was too low inside the cancerous environment and needs to be optimized for further attempts. However, Salmonella as carrier of enzymes like cytosine deaminase, thymidine kinase, or CPG2 have been successfully used in preclinical and clinical setups [70, 107, 111]. Nevertheless, the cohort of patients needs to be enlarged to significantly confirm the promising results.

The second approach concerns production and subsequent secretion or release of therapeutically active compounds by the bacteria themselves during tumor colonization. Therapeutic molecules include bacterial toxins like $\alpha$ Hemolysin or Azurin $[112,113]$, recombinant effector proteins such as mTNF- $\alpha$ and rIL-2 [114], or small hairpin RNAs (shRNAs) [115-117]. The delivery of these molecules across bacterial membranes to the extracellular environment represents a major challenge, although not in focus in many studies as long as beneficial effects are obtained. Most of such constructs do not contain obvious signals known to be required for excretion by Salmonella. Most likely, in these cases, the bacteria passively release the compounds upon lysis. Furthermore, despite the impressive therapeutic effect [117], it remains unclear whether the production of 
the effector proteins or shRNA is essentially required within the tumor or whether it is sufficient to deliver them in the periphery. To answer these questions, more studies should be performed. Nevertheless, most of the in vivo studies described thus far are held back by a lack of efficacy due to inefficient delivery of the compounds. Therefore, optimizations that would ensure controlled delivery may be of great advantage to increase therapeutic efficacy.

Two promising active delivery strategies for Gramnegative bacteria like Salmonella are currently under investigation. The first includes the aforementioned delayed lysis system. The advantage would be the controlled release of a therapeutic compound with a high concentration in a short period of time. However, it is a one-point release system and does not allow for continuous expression. Using this strategy, stimulation of the immune system may be too short-lived or the degradation of the compound may be too fast to treat the tumor in a sustained manner. Nevertheless, as the system has been successfully applied for vaccination purposes, its potential in cancer therapy should be explored as well.

The second strategy aims to exploit secretion systems that are already present in every bacterium [118, 119]. The basic idea is to fuse therapeutic compounds to signaling molecules that are essential for delivery via a particular secretion system. Thus the compounds would be continuously secreted. In order to obtain high tumor specificity, the application of inducible or tumor-specific promoters [54, 83, 120-125] may be preferred. However, the fusion to a signaling peptide could be a limiting factor to this strategy. The compound may lose its activity due to, for example, conformational alteration or incorrect refolding upon secretion. However, proof of principle has been successfully demonstrated by Singer et al., where recombinant neuroactive peptides were delivered via the flagellar type three secretion system (fT3SS) [126]. Furthermore, the efficacy of T3SS for delivery was assessed in a cancer vaccine, where the codon-optimized human tumorassociated antigen Survivin was genetically fused to sseJ. As a result, complete tumor regression was observed [127]. Thus, delivery via the T3SS of Salmonella may represent a promising foundation for active delivery.

Taken together, the possibility to deliver therapeutic compounds actively and directly to the site of interest may be the greatest advantage of bacteria and therefore it is worth placing further focus on this therapeutic application of bacteria. Results are promising and highlight with confidence a sustainable and opportune direction in bacteria mediated tumor therapy.

\section{Conclusion}

The specificity of cancer therapy for neoplastic tissue remains the most desirable trait. While many different strategies nowadays struggle to generate a sustainable targeted treatment, conventional therapies still remain the backbone of cancer remedies. However, they distinguish cancerous tissue from healthy tissue only by an increased proliferation rate. Therefore, room for improvement to such traditional therapies is evident. Furthermore, novel targeted therapies like the use of monoclonal antibodies or cell mediated immunotherapy are halted by applicability and costs and may yield therapeutic solutions to only a fraction of patients. With the need for a better general differentiator for cancer therapy, the great potential in tumor specificity that is intrinsic to bacteria should be exploited more readily not only for therapy but also for diagnosis as shown recently [128]. Focusing on the immunogenic therapeutic effect of bacteria alone might be insufficient. Intelligent exploitation of the unique tumor colonizing property for drug delivery could provide the next step needed to substantiate a more senseful and sustainable bacterial mediated tumor therapy that may pave the way to routine application in the clinics.

\section{Additional Points}

This review compares historical attempts with present ones of BMTT in order to give perspectives for future studies. It was not the intent to give a comprehensive review of all aspects present concerning BMTT. Therefore, we apologize to our colleagues whose work was not cited here. Note also that the title of this paper includes Renaissance of an Old Concept. Of course, this concept, born over 100 years ago, has received, and will most likely continue to receive, critical scrutiny.

\section{Conflict of Interests}

The authors declare that there is no conflict of interests regarding the publication of this paper.

\section{Authors' Contribution}

Sebastian Felgner, Dino Kocijancic, and Michael Frahm contributed equally to this work.

\section{Acknowledgments}

Sebastian Felgner was supported by the zoonosis Ph.D. program via a Lichtenberg Fellowship from the Niedersächsische Ministerium für Wissenschaft und Kultur. Dino Kocijancic was funded in part by the Hannover Biomedical Research School, Center for Infection Biology Program, and SymbioPharm ${ }^{\circledR}$.

\section{References}

[1] N. Howlader, A. Noone, M. Krapcho et al., SEER Cancer Statistics Review, 1975-2012, National Cancer Institute, Bethesda, Md, USA, 2014.

[2] S. Crawford, "Is it time for a new paradigm for systemic cancer treatment? Lessons from a century of cancer chemotherapy," Frontiers in Pharmacology, vol. 4, article 68, 2013.

[3] U. Ringborg and A. Platz, "Chemotherapy resistance mechanisms," Acta Oncologica, vol. 35, supplement 5, pp. 76-80, 1996.

[4] D. Hanahan and R. A. Weinberg, "The hallmarks of cancer," Cell, vol. 100, no. 1, pp. 57-70, 2000.

[5] K. R. Loeb and L. A. Loeb, "Significance of multiple mutations in cancer," Carcinogenesis, vol. 21, no. 3, pp. 379-385, 2000.

[6] D. Hanahan and R. A. Weinberg, "Hallmarks of cancer: the next generation,” Cell, vol. 144, no. 5, pp. 646-674, 2011. 
[7] F. Cavallo, C. De Giovanni, P. Nanni, G. Forni, and P.-L. Lollini, "2011: The immune hallmarks of cancer," Cancer Immunology, Immunotherapy, vol. 60, no. 3, pp. 319-326, 2011.

[8] G. P. Dunn, A. T. Bruce, H. Ikeda, L. J. Old, and R. D. Schreiber, "Cancer immunoediting: from immunosurveillance to tumor escape," Nature Immunology, vol. 3, no. 11, pp. 991-998, 2002.

[9] R. D. Schreiber, L. J. Old, and M. J. Smyth, "Cancer immunoediting: Integrating immunity's roles in cancer suppression and promotion," Science, vol. 331, no. 6024, pp. 1565-1570, 2011.

[10] C. G. Willett, D. G. Duda, E. dI Tomaso et al., "Complete pathological response to bevacizumab and chemoradiation in advanced rectal cancer," Nature Clinical Practice Oncology, vol. 4, no. 5, pp. 316-321, 2007.

[11] S. A. Rosenberg, N. P. Restifo, J. C. Yang, R. A. Morgan, and M. E. Dudley, "Adoptive cell transfer: a clinical path to effective cancer immunotherapy," Nature Reviews Cancer, vol. 8, no. 4, pp. 299-308, 2008.

[12] D. M. Pardoll, "The blockade of immune checkpoints in cancer immunotherapy," Nature Reviews Cancer, vol. 12, no. 4, pp. 252264, 2012.

[13] L. M. Weiner, R. Surana, and S. Wang, "Monoclonal antibodies: versatile platforms for cancer immunotherapy," Nature Reviews Immunology, vol. 10, no. 5, pp. 317-327, 2010.

[14] B. Ebbell, The Papyrus Ebers: The Greatest Egyptian Medical Document, Levin \& Munksgaard, Copenhagen, Denmark, 1937.

[15] N. P. Minton, J. M. Brown, P. Lambin, and J. Anné, “Clostridia in cancer therapy," in Clostridia, pp. 251-270, Wiley-VCH Verlag GmbH, New York, NY, USA, 2005.

[16] W. W. Cheyne, Recent Essays by Various Authors on Bacteria in Relation to Disease, The New Sydenham Society, London, UK, 1886.

[17] S. A. Hoption Cann, J. P. van Netten, and C. van Netten, "Dr William Coley and tumour regression: a place in history or in the future," Postgraduate Medical Journal, vol. 79, no. 938, pp. 672-680, 2003.

[18] W. B. Coley, "The treatment of inoperable sarcoma by bacterial toxins (the mixed toxins of the Streptococcus erysipelas and the Bacillus prodigiosus," Proceedings of the Royal Society of Medicine, vol. 3, pp. 1-48, 1910.

[19] W. B. Coley, "The treatment of inoperable sarcoma with the mixed toxins of Erysipelas and Bacillus prodigiosus. Immediate and final results in one hundred and forty cases," Journal of the American Medical Association, vol. 16, no. 9, pp. 456-465, 1898.

[20] E. F. McCarthy, "The toxins of William B. Coley and the treatment of bone and soft-tissue sarcomas," The Iowa Orthopaedic Journal, vol. 26, pp. 154-158, 2006.

[21] H. C. Nauts and W. E. Swift, “The treatment of malignant tumors by bacterial toxins as developed by the late William B. Coley, $\mathrm{MD}$, reviewed in the light of modern research," Cancer Research, vol. 6, pp. 205-216, 1946.

[22] H. C. Nauts, G. A. Fowler, and F. H. Bogatko, "A review of the influence of bacterial infection and of bacterial products (Coley's toxins) on malignant tumors in man; a critical analysis of 30 inoperable cases treated by Coley's mixed toxins, in which diagnosis was confirmed by microscopic examination selected for special study," Acta Medica Scandinavica, Supplementum, vol. 276, pp. 1-103, 1953.

[23] B. J. Johnston and E. T. Novales, "Clinical effect of Coley's toxin. A seven-year study," Cancer Chemotherapy Reports, vol. 21, pp. 43-68, 1962.
[24] C. Maletzki, U. Klier, W. Obst, B. Kreikemeyer, and M. Linnebacher, "Reevaluating the concept of treating experimental tumors with a mixed bacterial vaccine: coley's toxin," Clinical \& Developmental Immunology, vol. 2012, Article ID 230625, 16 pages, 2012.

[25] A. Morales, D. Eidinger, and A. W. Bruce, "Intracavitary Bacillus Calmette-Guerin in the treatment of superficial bladder tumors," The Journal of Urology, vol. 116, no. 2, pp. 180-183, 1976.

[26] G. Redelman-Sidi, G. Iyer, D. B. Solit, and M. S. Glickman, "Oncogenic activation of Pak1-dependent pathway of macropinocytosis determines BCG entry into bladder cancer cells," Cancer Research, vol. 73, no. 3, pp. 1156-1167, 2013.

[27] G. Redelman-Sidi, M. S. Glickman, and B. H. Bochner, "The mechanism of action of BCG therapy for bladder cancer-a current perspective," Nature Reviews Urology, vol. 11, no. 3, pp. 153-162, 2014.

[28] M. R. Saban, M. A. O’Donnell, R. E. Hurst et al., "Molecular networks discriminating mouse bladder responses to intravesical bacillus Calmette-Guerin (BCG), LPS, and TNF- $\alpha$," BMC Immunology, vol. 9, article 4, 2008.

[29] H. W. Sinn, B. D. Elzey, R. J. Jensen, X. Zhao, W. Zhao, and T. L. Ratliff, "The fibronectin attachment protein of bacillus Calmette-Guerin (BCG) mediates antitumor activity," Cancer Immunology, Immunotherapy, vol. 57, no. 4, pp. 573-579, 2008.

[30] D. Morrissey, G. C. O'Sullivan, and M. Tangney, "Tumour targeting with systemically administered bacteria," Current Gene Therapy, vol. 10, no. 1, pp. 3-14, 2010.

[31] R. K. Jain and N. S. Forbes, "Can engineered bacteria help control cancer?" Proceedings of the National Academy of Sciences of the United States of America, vol. 98, no. 26, pp. 14748-14750, 2001.

[32] Z.-Q. Hu and W.-H. Zhao, "Type 1 interferon-associated necroptosis: a novel mechanism for Salmonella enterica Typhimurium to induce macrophage death," Cellular \& Molecular Immunology, vol. 10, no. 1, pp. 10-12, 2013.

[33] K. Westphal, S. Leschner, J. Jablonska, H. Loessner, and S. Weiss, "Containment of tumor-colonizing bacteria by host neutrophils," Cancer Research, vol. 68, no. 8, pp. 2952-2960, 2008.

[34] N. J. Roberts, L. Zhang, F. Janku et al., "Intratumoral injection of Clostridium novyi-NT spores induces antitumor responses," Science Translational Medicine, vol. 6, no. 249, p. 249rall1, 2014.

[35] V. Staedtke, R. Bai, W. Sun et al., "Clostridium novyi-NT can cause regression of orthotopically implanted glioblastomas in rats," Oncotarget, vol. 6, no. 8, pp. 5536-5546, 2015.

[36] T. Ruby, L. McLaughlin, S. Gopinath, and D. Monack, "Salmonella's long-term relationship with its host," FEMS Microbiology Reviews, vol. 36, no. 3, pp. 600-615, 2012.

[37] E. Choe and R. A. Kazmierczak, "Phenotypic evolution of therapeutic Salmonella enterica serovar Typhimurium after invasion of TRAMP mouse prostate tumor," mBio: Journal Impact Factor \& Description, vol. 5, no. 4, pp. 1-8, 2014.

[38] S. Wang, Q. Kong, and R. Curtiss, "New technologies in developing recombinant attenuated Salmonella vaccine vectors," Microbial Pathogenesis, vol. 58, pp. 17-28, 2013.

[39] P. Chorobik, D. Czaplicki, K. Ossysek, and J. Bereta, "Salmonella and cancer: from pathogens to therapeutics," Acta Biochimica Polonica, vol. 60, no. 3, pp. 285-297, 2013.

[40] R. M. Hoffman and M. Zhao, "Methods for the development of tumor-targeting bacteria," Expert Opinion on Drug Discovery, vol. 9, no. 7, pp. 741-750, 2014. 
[41] K. B. Low, M. Ittensohn, X. Luo et al., "Construction of VNP20009," in Suicide Gene Therapy, vol. 90 of Methods in Molecular Medicine, pp. 47-59, Humana Press, New York, NY, USA, 2004

[42] R. M. Hoffman, "Tumor-seeking Salmonella amino acid auxotrophs," Current Opinion in Biotechnology, vol. 22, no. 6, pp. 917-923, 2011.

[43] M. Zhao, M. Yang, X.-M. Li et al., “Tumor-targeting bacterial therapy with amino acid auxotrophs of GFP-expressing Salmonella Typhimurium," Proceedings of the National Academy of Sciences of the United States of America, vol. 102, no. 3, pp. 755-760, 2005.

[44] Y. Zhang, N. Zhang, S. Su, R. M. Hoffman, and M. Zhao, "Salmonella Typhimurium A1-R tumor targeting in immunocompetent mice is enhanced by a traditional Chinese medicine herbal mixture," Anticancer Research, vol. 33, no. 5, pp. 18371844, 2013.

[45] M. Zhao, J. Geller, H. Ma, M. Yang, S. Penman, and R. M. Hoffman, "Monotherapy with a tumor-targeting mutant of Salmonella Typhimurium cures orthotopic metastatic mouse models of human prostate cancer," Proceedings of the National Academy of Sciences of the United States of America, vol. 104, no. 24, pp. 10170-10174, 2007.

[46] M. Zhao, A. Suetsugu, H. Ma et al., "Efficacy against lung metastasis with a tumor-targeting mutant of Salmonella Typhimurium in immunocompetent mice," Cell Cycle, vol. 11, no. 1, pp. 187-193, 2012.

[47] S. Miwa, S. Yano, Y. Zhang et al., "Tumor-targeting Salmonella Typhimurium A1-R prevents experimental human breast cancer bone metastasis in nude mice," Oncotarget, 2014.

[48] Y. Hiroshima, Y. Zhang, M. Zhao et al., "Tumor-targeting Salmonella Typhimurium A1-R in combination with Trastuzumab eradicates HER-2-positive cervical cancer cells in patientderived mouse models," PLOS ONE, vol. 10, no. 6, Article ID e0120358, 2015.

[49] A. Uchugonova, M. Zhao, Y. Zhang, M. Weinigel, K. König, and R. M. Hoffman, "Cancer-cell killing by engineered Salmonella imaged by multiphoton tomography in live mice," Anticancer Research, vol. 32, no. 10, pp. 4331-4337, 2012.

[50] Y. Hiroshima, M. Zhao, Y. Zhang et al., "Tumor-targeting Salmonella Typhimurium A1-R arrests a chemo-resistant patient soft-tissue sarcoma in nude mice," PLOS ONE, vol. 10, no. 8, Article ID e0134324, 2015.

[51] Y. Matsumoto, S. Miwa, Y. Zhang et al., "Intraperitoneal administration of tumor-targeting Salmonella Typhimurium A1-R inhibits disseminated human ovarian cancer and extends survival in nude mice," Oncotarget, vol. 6, no. 13, pp. 11369-11377, 2015.

[52] K. M. Broadway, E. A. P. Denson, R. V. Jensen, and B. E. Scharf, "Rescuing chemotaxis of the anticancer agent Salmonella enterica serovar Typhimurium VNP20009," Journal of Biotechnology, vol. 211, pp. 117-120, 2015.

[53] J. F. Toso, V. J. Gill, P. Hwu et al., "Phase I study of the intravenous administration of attenuated Salmonella Typhimurium to patients with metastatic melanoma," Journal of Clinical Oncology, vol. 20, no. 1, pp. 142-152, 2002.

[54] M. Frahm, S. Felgner, D. Kocijancic et al., "Efficiency of conditionally attenuated Salmonella enterica serovar Typhimurium in bacterium-mediated tumor therapy," mBio, vol. 6, no. 2, 2015.

[55] J. S. Eom, J. Seok Kim, J. Im Jang et al., "Enhancement of host immune responses by oral vaccination to Salmonella enterica serovar Typhimurium harboring both FliC and FljB Flagella," PLoS ONE, vol. 8, no. 9, Article ID e74850, 2013.

[56] S. M. Mangsbo, C. Ninalga, M. Essand, A. Loskog, and T. H. Tötterman, "CpG therapy is superior to BCG in an orthotopic bladder cancer model and generates $\mathrm{CD} 4^{+} \mathrm{T}$-cell immunity," Journal of Immunotherapy, vol. 31, no. 1, pp. 34-42, 2008.

[57] C. T. Nguyen, S. H. Hong, J.-I. Sin et al., "Flagellin enhances tumor-specific $\mathrm{CD}^{+} \mathrm{T}$ cell immune responses through TLR5 stimulation in a therapeutic cancer vaccine model," Vaccine, vol. 31, no. 37, pp. 3879-3887, 2013.

[58] S. Leschner and S. Weiss, "Salmonella-allies in the fight against cancer," Journal of Molecular Medicine, vol. 88, no. 8, pp. 763$773,2010$.

[59] S. Leschner, K. Westphal, N. Dietrich et al., “Tumor invasion of Salmonella enterica serovar Typhimurium is accompanied by strong hemorrhage promoted by TNF- $\alpha$," PLoS ONE, vol. 4, no. 8, Article ID e6692, 2009.

[60] K. Crull, D. Bumann, and S. Weiss, "Influence of infection route and virulence factors on colonization of solid tumors by Salmonella enterica serovar Typhimurium," FEMS Immunology and Medical Microbiology, vol. 62, no. 1, pp. 75-83, 2011.

[61] C. Stern, N. Kasnitz, D. Kocijancic et al., "Induction of CD4 $4^{+}$ and $\mathrm{CD}^{+}$anti-tumor effector $\mathrm{T}$ cell responses by bacteria mediated tumor therapy," International Journal of Cancer, vol. 137, no. 8, pp. 2019-2028, 2015.

[62] P. C. Maciag, S. Radulovic, and J. Rothman, “The first clinical use of a live-attenuated Listeria monocytogenes vaccine: a Phase I safety study of Lm-LLO-E7 in patients with advanced carcinoma of the cervix," Vaccine, vol. 27, no. 30, pp. 3975-3983, 2009.

[63] V. Shahabi, P. C. Maciag, S. Rivera, and A. Wallecha, "Live, attenuated strains of Listeria and Salmonella as vaccine vectors in cancer treatment," Bioengineered Bugs, vol. 1, no. 4, pp. 237$245,2010$.

[64] D. T. Le, D. G. Brockstedt, R. Nir-Paz et al., "A live-attenuated Listeria vaccine (ANZ-100) and a live-attenuated Listeria vaccine expressing mesothelin (CRS-207) for advanced cancers: phase I studies of safety and immune induction," Clinical Cancer Research, vol. 18, no. 3, pp. 858-868, 2012.

[65] S. Barbé, L. Van Mellaert, and J. Anné, “The use of clostridial spores for cancer treatment," Journal of Applied Microbiology, vol. 101, no. 3, pp. 571-578, 2006.

[66] L. Van Mellaert, S. Barbé, and J. Anné, “Clostridium spores as anti-tumour agents," Trends in Microbiology, vol. 14, no. 4, pp. 190-196, 2006.

[67] E. L. Krick, K. U. Sorenmo, S. C. Rankin et al., "Evaluation of Clostridium novyi-NT spores in dogs with naturally occurring tumors," American Journal of Veterinary Research, vol. 73, no. 1, pp. 112-118, 2012.

[68] C. Stern, The Essential Effector Role of T Cellsin BacteriaMediated Tumor Therapy, HZI, 2012.

[69] D. H. Thamm, I. D. Kurzman, I. King et al., "Systemic administration of an attenuated, tumor-targeting Salmonella Typhimurium to dogs with spontaneous neoplasia: phase I evaluation," Clinical Cancer Research, vol. 11, no. 13, pp. 48274834, 2005.

[70] J. M. Pawelek, K. B. Low, and D. Bermudes, "Tumor-targeted Salmonella as a novel anticancer vector," Cancer Research, vol. 57, no. 20, pp. 4537-4544, 1997. 
[71] K. B. Low, M. Ittensohn, T. Le et al., "Lipid a mutant Salmonella with suppressed virulence and TNF $\alpha$ induction retain tumortargeting in vivo," Nature Biotechnology, vol. 17, no. 1, pp. 37-41, 1999.

[72] B. D. Needham, S. M. Carroll, D. K. Giles, G. Georgiou, M. Whiteley, and M. S. Trent, "Modulating the innate immune response by combinatorial engineering of endotoxin," Proceedings of the National Academy of Sciences of the United States of America, vol. 110, no. 4, pp. 1464-1469, 2013.

[73] D. Mandell and J. E. Bennett, Principles and Practice of Infectious Diseases, Elsevier, Philadelphia, Pa, USA, 7th edition, 2010.

[74] L. R. Zacharski and V. P. Sukhatme, "Coley's toxin revisited: immunotherapy or plasminogen activator therapy of cancer?" Journal of Thrombosis and Haemostasis, vol. 3, no. 3, pp. 424427, 2005.

[75] C.-H. Lee, C.-L. Wu, and A.-L. Shiau, "Toll-like receptor 4 mediates an antitumor host response induced by Salmonella choleraesuis," Clinical Cancer Research, vol. 14, no. 6, pp. 19051912, 2008.

[76] S. Kaimala, Y. A. Mohamed, N. Nader et al., "Salmonellamediated tumor regression involves targeting of tumor myeloid suppressor cells causing a shift to M1-like phenotype and reduction in suppressive capacity," Cancer Immunology, Immunotherapy, vol. 63, no. 6, pp. 587-599, 2014.

[77] N. Goutagny, Y. Estornes, U. Hasan, S. Lebecque, and C. Caux, "Targeting pattern recognition receptors in cancer immunotherapy," Targeted Oncology, vol. 7, no. 1, pp. 29-54, 2012.

[78] F. Hayashi, K. D. Smith, A. Ozinsky et al., "The innate immune response to bacterial flagellin is mediated by Toll-like receptor 5," Nature, vol. 410, no. 6832, pp. 1099-1103, 2001.

[79] Q. Kong, J. Yang, Q. Liu, P. Alamuri, K. L. Roland, and R. Curtiss III, "Effect of deletion of genes involved in lipopolysaccharide core and $\mathrm{O}$-antigen synthesis on virulence and immunogenicity of Salmonella enterica serovar Typhimurium," Infection and Immunity, vol. 79, no. 10, pp. 4227-4239, 2011.

[80] G. Nagy, V. Danino, U. Dobrindt et al., "Down-regulation of key virulence factors makes the Salmonella enterica serovar Typhimurium $\mathrm{rfaH}$ mutant a promising live-attenuated vaccine candidate," Infection and Immunity, vol. 74, no. 10, pp. 59145925, 2006.

[81] C. K. Schmitt, S. C. Darnell, V. L. Tesh, B. A. D. Stocker, and A. D. O'Brien, "Mutation of flgM attenuates virulence of Salmonella Typhimurium, and mutation of $f l i A$ represses the attenuated phenotype," Journal of Bacteriology, vol. 176, no. 2, pp. 368-377, 1994.

[82] S. K. Hoiseth and B. A. D. Stocker, "Aromatic-dependent Salmonella Typhimurium are non-virulent and effective as live vaccines," Nature, vol. 291, no. 5812, pp. 238-239, 1981.

[83] N. Arrach, P. Cheng, M. Zhao, C. A. Santiviago, R. M. Hoffman, and M. McClelland, "High-throughput screening for Salmonella avirulent mutants that retain targeting of solid tumors," Cancer Research, vol. 70, no. 6, pp. 2165-2170, 2010.

[84] M. K. Stewart, L. A. Cummings, M. L. Johnson, A. B. Berezow, and B. T. Cookson, "Regulation of phenotypic heterogeneity permits Salmonella evasion of the host caspase-1 inflammatory response," Proceedings of the National Academy of Sciences of the United States of America, vol. 108, no. 51, pp. 20742-20747, 2011.

[85] E. A. Miao and J. V. Rajan, "Salmonella and caspase-1: a complex interplay of detection and evasion," Frontiers in Microbiology, vol. 2, article 85, 2011.
[86] J. A. Hagar, D. A. Powell, Y. Aachoui, R. K. Ernst, and E. A. Miao, "Cytoplasmic LPS activates caspase-11: implications in TLR4independent endotoxic shock," Science, vol. 341, no. 6151, pp. 1250-1253, 2013.

[87] S.-I. Saitoh, S. Akashi, T. Yamada et al., "Lipid A antagonist, lipid IVa, is distinct from lipid A in interaction with Toll-like receptor 4 (TLR4)-MD-2 and ligand-induced TLR4 oligomerization," International Immunology, vol. 16, no. 7, pp. 961-969, 2004.

[88] Q. Kong, D. A. Six, Q. Liu et al., "Palmitoylation state impacts induction of innate and acquired immunity by the Salmonella enterica serovar Typhimurium $m s b B$ mutant," Infection and Immunity, vol. 79, no. 12, pp. 5027-5038, 2011.

[89] J. S. Eom, J. Seok Kim, J. Im Jang et al., "Enhancement of host immune responses by oral vaccination to Salmonella enterica serovar Typhimurium harboring both FliC and FljB flagella," PLoS ONE, vol. 8, no. 9, Article ID e74850, 2013.

[90] J. E. Olsen, K. H. Hoegh-Andersen, J. Casadesús, J. Rosenkranzt, M. S. Chadfield, and L. E. Thomsen, "The role of flagella and chemotaxis genes in host pathogen interaction of the host adapted Salmonella enterica serovar Dublin compared to the broad host range serovar S. Typhimurium," BMC Microbiology, vol. 13, article 67, 2013.

[91] M. D. Juárez-Rodríguez, J. Yang, R. Kader, P. Alamuri, R. Curtiss III, and J. E. Clark-Curtiss, "Live attenuated Salmonella vaccines displaying regulated delayed lysis and delayed antigen synthesis to confer protection against Mycobacterium tuberculosis," Infection and Immunity, vol. 80, no. 2, pp. 815-831, 2012.

[92] Q. Kong, Q. Liu, A. M. Jansen, and R. Curtiss, "Regulated delayed expression of $r f c$ enhances the immunogenicity and protective efficacy of a heterologous antigen delivered by live attenuated Salmonella enterica vaccines," Vaccine, vol. 28, no. 37, pp. 6094-6103, 2010.

[93] Q. Kong, Q. Liu, K. L. Roland, and R. Curtiss III, "Regulated delayed expression of $r f a H$ in an attenuated Salmonella enterica serovar Typhimurium vaccine enhances immunogenicity of outer membrane proteins and a heterologous antigen," Infection and Immunity, vol. 77, no. 12, pp. 5572-5582, 2009.

[94] W. Kong, M. Brovold, B. A. Koeneman, J. Clark-Curtiss, and R. Curtiss III, "Turning self-destructing Salmonella into a universal DNA vaccine delivery platform," Proceedings of the National Academy of Sciences of the United States of America, vol. 109, no. 47, pp. 19414-19419, 2012.

[95] P. Łaniewski, M. Kuczkowski, K. Chrzastek et al., "Evaluation of the immunogenicity of Campylobacter jejuni CjaA protein delivered by Salmonella enterica sv. Typhimurium strain with regulated delayed attenuation in chickens," World Journal of Microbiology \& Biotechnology, vol. 30, no. 1, pp. 281-292, 2014.

[96] R. Curtiss III, S.-Y. Wanda, B. M. Gunn et al., "Salmonella enterica serovar Typhimurium strains with regulated delayed attenuation in vivo," Infection and Immunity, vol. 77, no. 3, pp. 1071-1082, 2009.

[97] W. Kong, S.-Y. Wanda, X. Zhang et al., "Regulated programmed lysis of recombinant Salmonella in host tissues to release protective antigens and confer biological containment," Proceedings of the National Academy of Sciences of the United States of America, vol. 105, no. 27, pp. 9361-9366, 2008.

[98] S. Ashraf, W. Kong, S. Wang, J. Yang, and R. Curtiss, "Protective cellular responses elicited by vaccination with influenza nucleoprotein delivered by a live recombinant attenuated Salmonella vaccine," Vaccine, vol. 29, no. 23, pp. 3990-4002, 2011. 
[99] Y. Hiroshima, M. Zhao, Y. Zhang et al., "Comparison of efficacy of Salmonella Typhimurium A1-R and chemotherapy on stemlike and non-stem human pancreatic cancer cells," Cell Cycle, vol. 12, no. 17, pp. 2774-2780, 2013.

[100] L.-J. Jia, H.-M. Xu, D.-Y. Ma et al., "Enhanced therapeutic effect by combination of tumor-targeting Salmonella and endostatin in murine melanoma model," Cancer Biology \& Therapy, vol. 4, no. 8, pp. 840-845, 2005.

[101] S. Topalian, C. Drake, and D. Pardoll, "Immune checkpoint blockade: a common denominator approach to cancer therapy," Cancer Cell, vol. 27, no. 4, pp. 450-461, 2015.

[102] D. C. Binder, B. Engels, A. Arina et al., "Antigen-specific bacterial vaccine combined with anti-PD-L1 rescues dysfunctional endogenous T cells to reject long-established cancer," Cancer Immunology Research, vol. 1, no. 2, pp. 123-133, 2013.

[103] S. S. Kwek, E. Cha, and L. Fong, "Unmasking the immune recognition of prostate cancer with CTLA4 blockade," Nature Reviews Cancer, vol. 12, no. 4, pp. 289-297, 2012.

[104] N. S. Forbes, "Engineering the perfect (bacterial) cancer therapy," Nature Reviews Cancer, vol. 10, no. 11, pp. 785-794, 2010.

[105] L. K. Green, M. A. Storey, E. M. Williams et al., "The flavin reductase $\mathrm{MsuE}$ is a novel nitroreductase that can efficiently activate two promising next-generation prodrugs for genedirected enzyme prodrug therapy," Cancers, vol. 5, no. 3, pp. 985-997, 2013.

[106] J. Theys, W. Landuyt, S. Nuyts et al., "Specific targeting of cytosine deaminase to solid tumors by engineered Clostridium acetobutylicum," Cancer Gene Therapy, vol. 8, no. 4, pp. 294-297, 2001.

[107] J. Nemunaitis, C. Cunningham, N. Senzer et al., "Pilot trial of genetically modified, attenuated Salmonella expressing the E. coli cytosine deaminase gene in refractory cancer patients," Cancer Gene Therapy, vol. 10, no. 10, pp. 737-744, 2003.

[108] A. M. Kubiak and N. P. Minton, "The potential of clostridial spores as therapeutic delivery vehicles in tumour therapy," Research in Microbiology, vol. 166, no. 4, pp. 244-254, 2015.

[109] J. Stritzker, S. Pilgrim, A. A. Szalay, and W. Goebel, "Prodrug converting enzyme gene delivery by L. monocytogenes," BMC Cancer, vol. 8, article 94, 2008.

[110] S.-C. Liu, G.-O. Ahn, M. Kioi, M.-J. Dorie, A. V. Patterson, and J. M. Brown, "Optimized Clostridium-directed enzyme prodrug therapy improves the antitumor activity of the novel DNA cross-linking agent PR-104," Cancer Research, vol. 68, no. 19, pp. 7995-8003, 2008.

[111] F. Friedlos, P. Lehouritis, L. Ogilvie et al., "Attenuated Salmonella targets prodrug activating enzyme carboxypeptidase G2 to mouse melanoma and human breast and colon carcinomas for effective suicide gene therapy," Clinical Cancer Research, vol. 14, no. 13, pp. 4259-4266, 2008.

[112] C. A. Swofford, A. T. St Jean, J. T. Panteli, Z. J. Brentzel, and N. S. Forbes, "Identification of Staphylococcus aureus $\alpha$-hemolysin as a protein drug that is secreted by anticancer bacteria and rapidly kills cancer cells," Biotechnology and Bioengineering, vol. 111, no. 6, pp. 1233-1245, 2014.

[113] A. T. St Jean, C. A. Swofford, J. T. Panteli, Z. J. Brentzel, and N. S. Forbes, "Bacterial delivery of Staphylococcus aureus $\alpha$ Hemolysin causes regression and necrosis in murine tumors," Molecular Therapy, vol. 22, no. 7, pp. 1266-1274, 2014.

[114] S. Barbé, L. Van Mellaert, J. Theys et al., "Secretory production of biologically active rat interleukin-2 by Clostridium acetobutylicum DSM792 as a tool for anti-tumor treatment," FEMS Microbiology Letters, vol. 246, no. 1, pp. 67-73, 2005.
[115] N. Yang, X. Zhu, L. Chen, S. Li, and D. Ren, "Oral administration of attenuated $S$. typhimurium carrying shRNA-expressing vectors as a cancer therapeutic," Cancer Biology \& Therapy, vol. 7, no. 1, pp. 145-151, 2008.

[116] Y. Tian, B. Guo, H. Jia et al., “Targeted therapy via oral administration of attenuated Salmonella expression plasmidvectored Stat3-shRNA cures orthotopically transplanted mouse HCC," Cancer Gene Therapy, vol. 19, no. 6, pp. 393-401, 2012.

[117] C. A. Blache, E. R. Manuel, T. I. Kaltcheva et al., "Systemic delivery of Salmonella Typhimurium transformed with IDO shRNA enhances intratumoral vector colonization and suppresses tumor growth," Cancer Research, vol. 72, no. 24, pp. 6447-6456, 2012.

[118] R. Fronzes, P. J. Christie, and G. Waksman, "The structural biology of type IV secretion systems," Nature Reviews Microbiology, vol. 7, no. 10, pp. 703-714, 2009.

[119] C. Stathopoulos, D. R. Hendrixson, D. G. Thanassi, S. J. Hultgren, J. W. St Geme III, and R. Curtiss III, "Secretion of virulence determinants by the general secretory pathway in Gram-negative pathogens: an evolving story," Microbes and Infection, vol. 2, no. 9, pp. 1061-1072, 2000.

[120] C. A. Swofford, N. Van Dessel, and N. S. Forbes, "Quorumsensing Salmonella selectively trigger protein expression within tumors," Proceedings of the National Academy of Sciences of the United States of America, vol. 112, no. 11, pp. 3457-3462, 2015.

[121] J. Hardcastle, K. Kurozumi, E. A. Chiocca, and B. Kaur, "Oncolytic viruses driven by tumor-specific promoters," Current Cancer Drug Targets, vol. 7, no. 2, pp. 181-189, 2007.

[122] S. Leschner, I. V. Deyneko, S. Lienenklaus et al., "Identification of tumor-specific Salmonella Typhimurium promoters and their regulatory logic," Nucleic Acids Research, vol. 40, no. 7, pp. 2984-2994, 2012.

[123] H. Loessner, S. Leschner, A. Endmann et al., "Drug-inducible remote control of gene expression by probiotic Escherichia coli Nissle 1917 in intestine, tumor and gall bladder of mice," Microbes and Infection, vol. 11, no. 14-15, pp. 1097-1105, 2009.

[124] H. Loessner, A. Endmann, S. Leschner et al., "Remote control of tumour-targeted Salmonella enterica serovar Typhimurium by the use of l-arabinose as inducer of bacterial gene expression in vivo," Cellular Microbiology, vol. 9, no. 6, pp. 1529-1537, 2007.

[125] N. Arrach, M. Zhao, S. Porwollik, R. M. Hoffman, and M. McClelland, "Salmonella promoters preferentially activated inside tumors," Cancer Research, vol. 68, no. 12, pp. 4827-4832, 2008.

[126] H. M. Singer, M. Erhardt, A. M. Steiner et al., "Selective purification of recombinant neuroactive peptides using the flagellar type III secretion system," mBio, vol. 3, no. 3, 2012.

[127] X. Xu, W. A. H. Hegazy, L. Guo et al., "Effective cancer vaccine platform based on attenuated Salmonella and a type III secretion system," Cancer Research, vol. 74, no. 21, pp. 6260-6270, 2014.

[128] S. Yano, Y. Zhang, M. Zhao et al., “Tumor-targeting Salmonella Typhimurium A1-R decoys quiescent cancer cells to cycle as visualized by FUCCI imaging and become sensitive to chemotherapy," Cell Cycle, vol. 13, no. 24, pp. 3958-3963, 2014.

[129] K. Yazawa, M. Fujimori, T. Nakamura et al., "Bifidobacterium longum as a delivery system for gene therapy of chemically induced rat mammary tumors," Breast Cancer Research and Treatment, vol. 66, no. 2, pp. 165-170, 2001.

[130] P. H. Lizotte, J. R. Baird, C. A. Stevens et al., "Attenuated Listeria monocytogenes reprograms M2-polarized tumor-associated macrophages in ovarian cancer leading to iNOS-mediated 
tumor cell lysis," OncoImmunology, vol. 3, no. 5, Article ID e28926, 2014.

[131] B. P. Keenan, Y. Saenger, M. I. Kafrouni et al., "A Listeria vaccine and depletion of t-regulatory cells activate immunity against early stage pancreatic intraepithelial neoplasms and prolong survival of mice," Gastroenterology, vol. 146, no. 7, pp. 1784.e61794.e6, 2014.

[132] Y. Zhang, Y. Tome, A. Suetsugu et al., "Determination of the optimal route of administration of Salmonella Typhimurium A1-R to target breast cancer in nude mice," Anticancer Research, vol. 32, no. 7, pp. 2501-2508, 2012.

[133] M. Momiyama, M. Zhao, H. Kimura et al., "Inhibition and eradication of human glioma with tumor-targeting Salmonella Typhimurium in an orthotopic nude-mouse model," Cell Cycle, vol. 11, no. 3, pp. 628-632, 2012.

[134] Y. Hiroshima, Y. Zhang, T. Murakami et al., "Efficacy of tumor-targeting Salmonella Typhimurium Al-R in combination with anti-angiogenesis therapy on a pancreatic cancer patientderived orthotopic xenograft (PDOX) and cell line mouse models," Oncotarget, vol. 5, no. 23, pp. 12346-12357, 2014.

[135] C.-C. Chen, W.-C. Lin, M.-S. Kong et al., "Oral inoculation of probiotics Lactobacillus acidophilus NCFM suppresses tumour growth both in segmental orthotopic colon cancer and extraintestinal tissue," British Journal of Nutrition, vol. 107, no. 11, pp. 1623-1634, 2012.

[136] D. T. Le, A. Wang-Gillam, V. Picozzi et al., "Safety and survival with GVAX pancreas prime and Listeria monocytogenes expressing Mesothelin (CRS-207) boost vaccines for metastatic pancreatic cancer," Journal of Clinical Oncology, vol. 33, no. 12, pp. 1325-1333, 2015. 

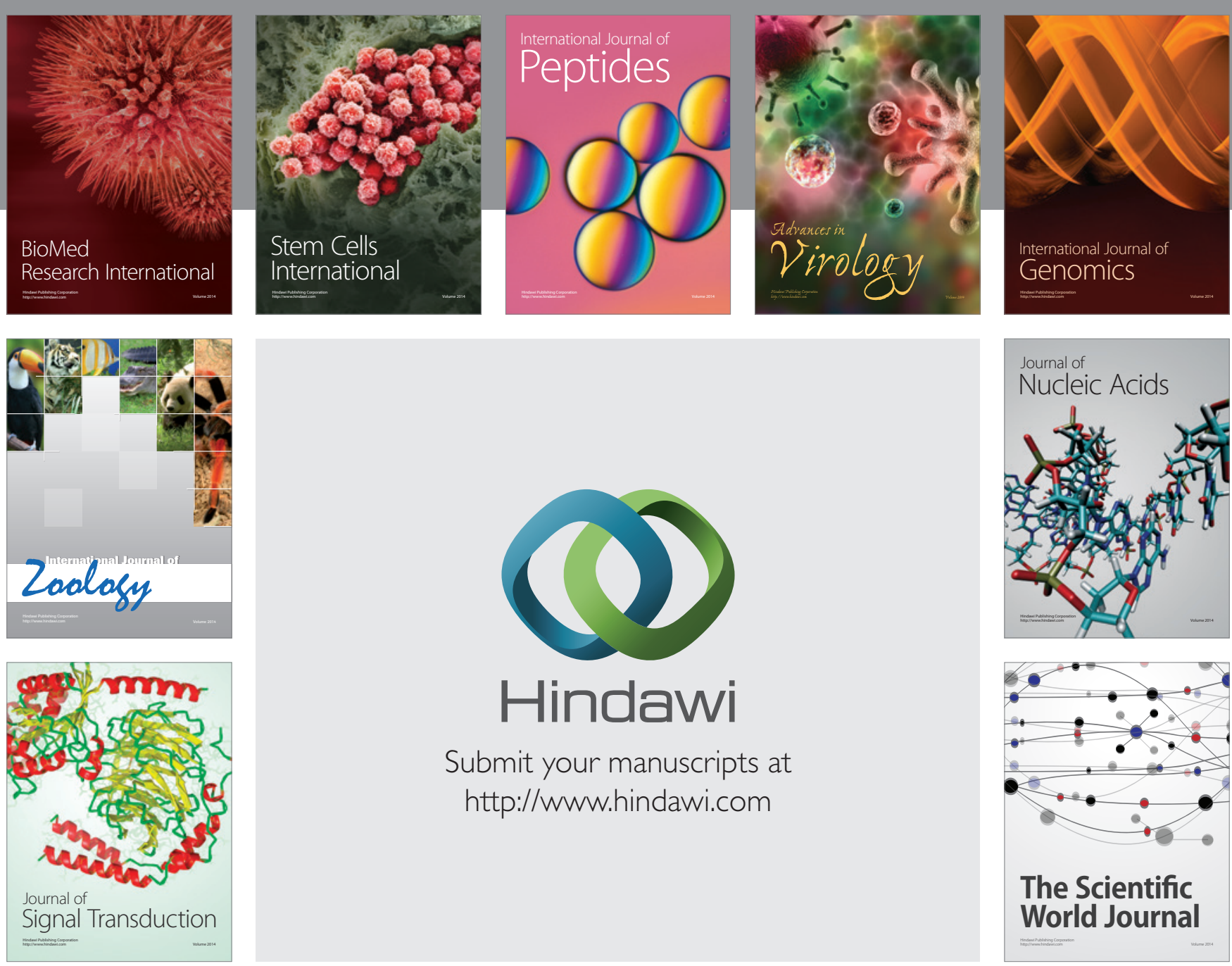

Submit your manuscripts at

http://www.hindawi.com
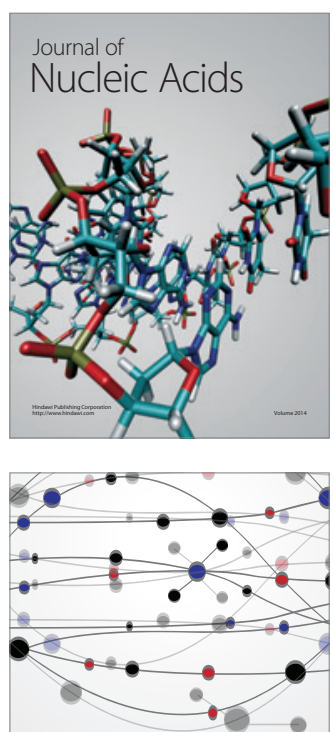

The Scientific World Journal
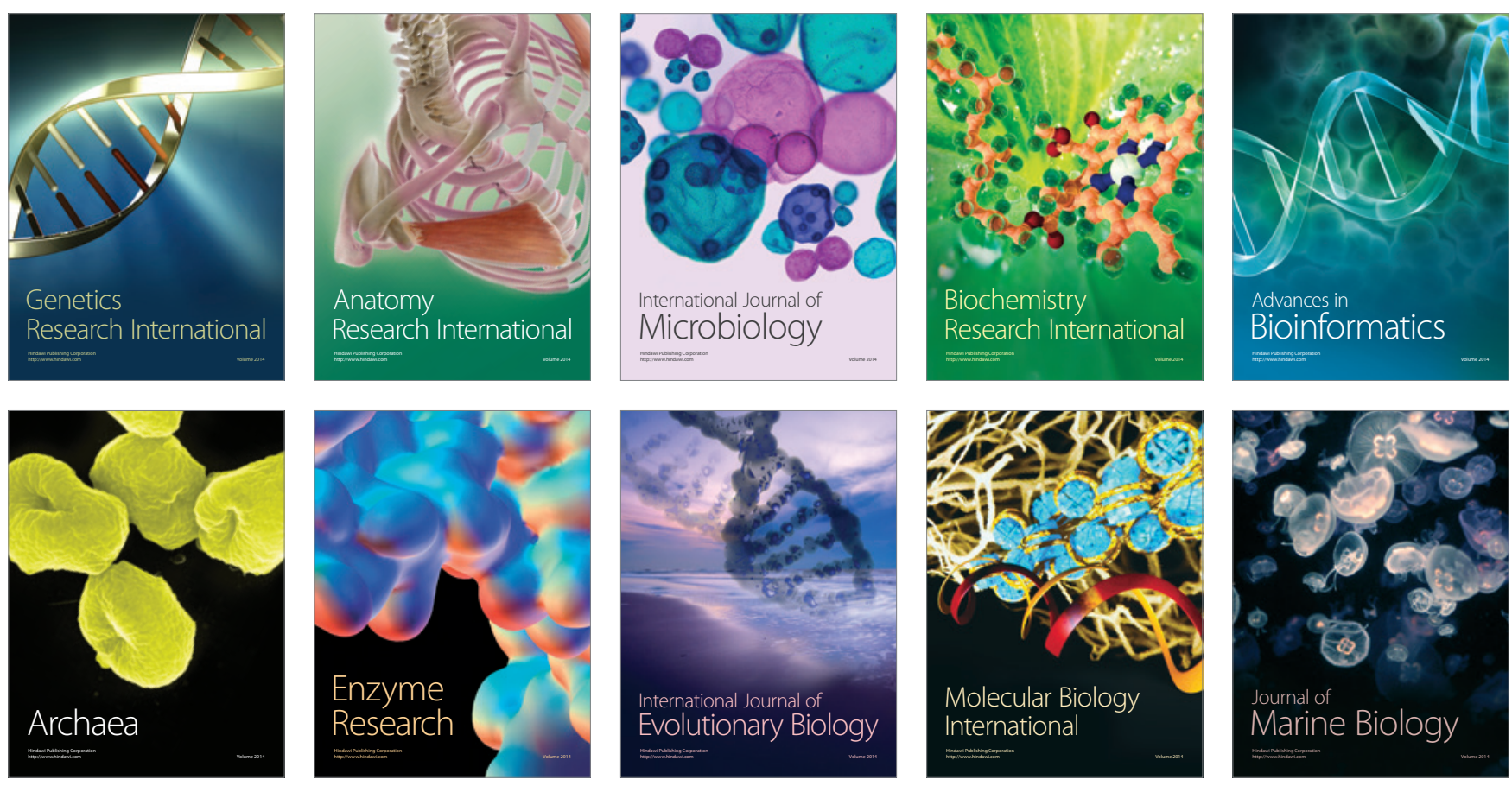